\title{
Percepção de professores e alunos sobre os impactos ambientais associados à mineração
}

\author{
Perception of teachers and students about the environmental impacts \\ associated with mining
}

\author{
Percepción de docentes y estudiantes sobre los impactos ambientales \\ asociados con la minería
}

\author{
Clayton Angelo Silva Costa ${ }^{1}$ \\ Paulina Maria Maia Barbosa ${ }^{2}$ \\ Sónia Maria Carvalho Ribeiro ${ }^{3}$ \\ Henrique Godoy Corsetti Purcino ${ }^{4}$
}

\begin{abstract}
Resumo
A mineração é uma atividade importante, mas pode gerar impactos socioambientais. Reconhecendo esses impactos, parte das mineradoras desenvolve programas de Educação Ambiental (EA) através de ações de Responsabilidade Social Corporativa (RSC). O estudo foi realizado no município de Congonhas, estado de Minas Gerais, Brasil, inserido no Quadrilátero Ferrífero, uma das maiores províncias de minério de ferro do mundo. O objetivo foi analisar como a atual percepção dos professores e alunos contribui com a construção de projetos e práticas educativas que favoreçam a participação crítica nos programas de RSC. Análises qualitativas e quantitativas foram empregadas. Os resultados mostram que parte dos professores e dos alunos desconhece as atividades de RSC e $92 \%$ dos professores trabalham EA de forma autodidata. É necessário abordar a percepção e a geoética nos projetos ambientais, por meio de metodologias participativas, para que a atual percepção dos atores contribua para sua participação crítica nos programas de RSC.
\end{abstract}

Palavras-Chave: Geoética. Educação Socioambiental. Responsabilidade Social Corporativa.

\begin{abstract}
Mining is an important activity, but it can generate socio-environmental impacts. Recognizing these impacts, somemining companies develop Environmental Education (EA) programs through actions of Corporate Social Responsibility (CSR). The study was carried out in the municipality of Congonhas, state of Minas Gerais, Brazil, inserted in the Quadrilátero Ferrífero, one of the largest iron ore provinces in the world. The objective was to analyze how the current perception of teachers and students contributes to the construction of educational projects and practices that favor critical participation in CSR programs. Qualitative and quantitative analyses were used. The results show that part of the teachers and students are unaware of the CSR activities and $92 \%$ of the teachers work in a self-taught way. It is necessary to address the perception and geoethics in environmental projects through participatory methodologies in order for the current perception of the actors to contribute to their critical participation in CSR programs.
\end{abstract}

Keywords: Geoethics. Socioenvironmental Education. Corporate social responsibility.

\section{Resumen}

La minería es una actividad importante, pero puede generar impactos socioambientales. Reconociendo estos impactos, parte de las compañías mineras desarrolla programas de Educación Ambiental (EA) a través de acciones de Responsabilidad Social Corporativa (RSC). El estudio se llevó a cabo en el municipio de Congonhas, estado de Minas Gerais, Brasil, insertado en el Quadrilátero Ferrífero, una de las provincias de mineral de hierro más grandes del mundo. El objetivo era analizar cómo la percepción actual de docentes y estudiantes contribuye a la construcción de proyectos y prácticas educativas que favorecen la participación crítica en los programas de RSE. Se utilizaron análisis cualitativos y cuantitativos. Los resultados muestran que

\footnotetext{
${ }^{1}$ Professor efetivo do Departamento de Geociências, CEFET-MG. clayton@ @efetmg.br

${ }^{2}$ Professora efetiva do ICB (Instituto de Ciências Biológicas), UFMG. maia@icb.ufmg.br

${ }^{3}$ Professora efetiva do Departamento de Cartografia, UFMG. soniacarvalhoribeiro@ cart.igc.ufmg.br

${ }^{4}$ Consultor ambiental, Autônomo (Prestação de serviços/consultoria). henriquegodoypurcino@ gmail.com
} 
parte de los maestros y estudiantes desconocen las actividades de RSE y el $92 \%$ de los maestros trabajan de manera autodidacta. Es necesario abordar la percepción y la geoética en proyectos ambientales a través de metodologías participativas para que la percepción actual de los actores contribuya a su participación crítica en los programas de RSE.

Palabras clave: Geoética. Educación Socioambiental. Responsabilidad social corporativa.

\section{Introdução}

A crescente demanda por minério de ferro aumenta a preocupação da comunidade internacional em relação aos impactos associados à mineração. De acordo com Kitula (2006), esses impactos são potencialmente adversos para a natureza, o patrimônio cultural, a saúde e a segurança de comunidades. Pereira, Costa e Borges (2017) acrescentam que os impactos da mineração podem aumentar os conflitos socioambientais e comprometer a qualidade de vida de comunidades. A percepção das pessoas precisa ser considerada na elaboração de projetos ambientais para amenizar as adversidades apresentadas por meio da identificação, interpretação e compreensão de tais conflitos.

No processo de elaboração de projetos, uma abordagem na perspectiva da geoética também pode ser considerada como fator contribuinte para a percepção das pessoas quanto ao uso dos recursos naturais face aos fenômenos ecológicos (GOBSTER; NASSAUER; DANIEL, 2007). A Geoética é considerada uma área das Geociências que aborda os desdobramentos éticos, sociais e culturais relacionados à percepção dos impactos associados ao uso dos recursos geológicos (CASTRO; RUCHKYS; MANINI, 2018). Tais desdobramentos, oriundos da geoética, podem ser contextualizados em projetos ambientais a fim de contribuir e ampliar a percepção dos indivíduos através da sensação de se perceberem como parte integrante de seu lugar vivido. Tuan (2012) acredita que a percepção gera uma ponte afetiva entre o indivíduo e o lugar, o que resulta em experiência pessoal. Algumas mineradoras têm valorizado a importância da percepção da comunidade em relação às experiências vividas em seu lugar. De acordo com Veiga, Scoble e Mcallister (2001), parte das mineradoras tem promovido consultas pautadas na percepção das comunidades a respeito do processo produtivo minerário e suas implicações no lugar.

Essa importância também é reconhecida pela Unesco (2017) no Programa 13: Percepção da Qualidade Ambiental, que menciona a necessidade dos estudos sobre percepção para a gestão de lugares e paisagens. Parte das mineradoras ainda não aborda a percepção em seus programas de Responsabilidade Social Corporativa (RSC) para atender as necessidades das comunidades localizadas em seu entorno (MÉNDEZ; RODRÍGUEZ, 2016). Segundo os autores, a RSC refere-se ao interesse das empresas em adotar uma postura socialmente responsável no tratamento de injustiças ambientais e degradação da natureza, criando estratégias de investimentos sociais envolvendo as partes interessadas.

Neste estudo, consideramos a percepção como parte representativa da relação mineração-comunidade-lugar. Esta pesquisa foi realizada junto aos professores e alunos de escolas municipais situadas na cidade de Congonhas, no estado de Minas Gerais, Brasil. A cidade de Congonhas está localizada na região do Quadrilátero Ferrífero, que se destaca pela intensa atividade de extração de minério de ferro (OLIVEIRA et al., 2017).

Este estudo avaliou a percepção de professores e alunos da rede municipal de ensino em relação aos impactos associados à mineração. A questão que este estudo busca responder é como a atual percepção desses atores pode contribuir para a construção de práticas educativas e, com isso, promover uma participação crítica de professores e alunos nos programas de Responsabilidade Social Coorporativa (RSC) no município de Congonhas, Minas Gerais.

\section{Procedimentos Metodológicos}




\section{1 Área de estudo}

O município de Congonhas está localizado no estado de Minas Gerais, Brasil. A área territorial do município é de aproximadamente $304,06 \mathrm{~km}^{2}$ e sua população é de 48.519 habitantes. O município faz parte do Quadrilátero Ferrífero (QF) (Figura 1), considerado uma das maiores províncias de minério de ferro do Brasil, com uma área de, aproximadamente, $7.200 \mathrm{~km}^{2}$. A cidade contribui com 7,5\% do PIB relativo à indústria extrativista mineral do estado de Minas Gerais (IBGE, 2013).

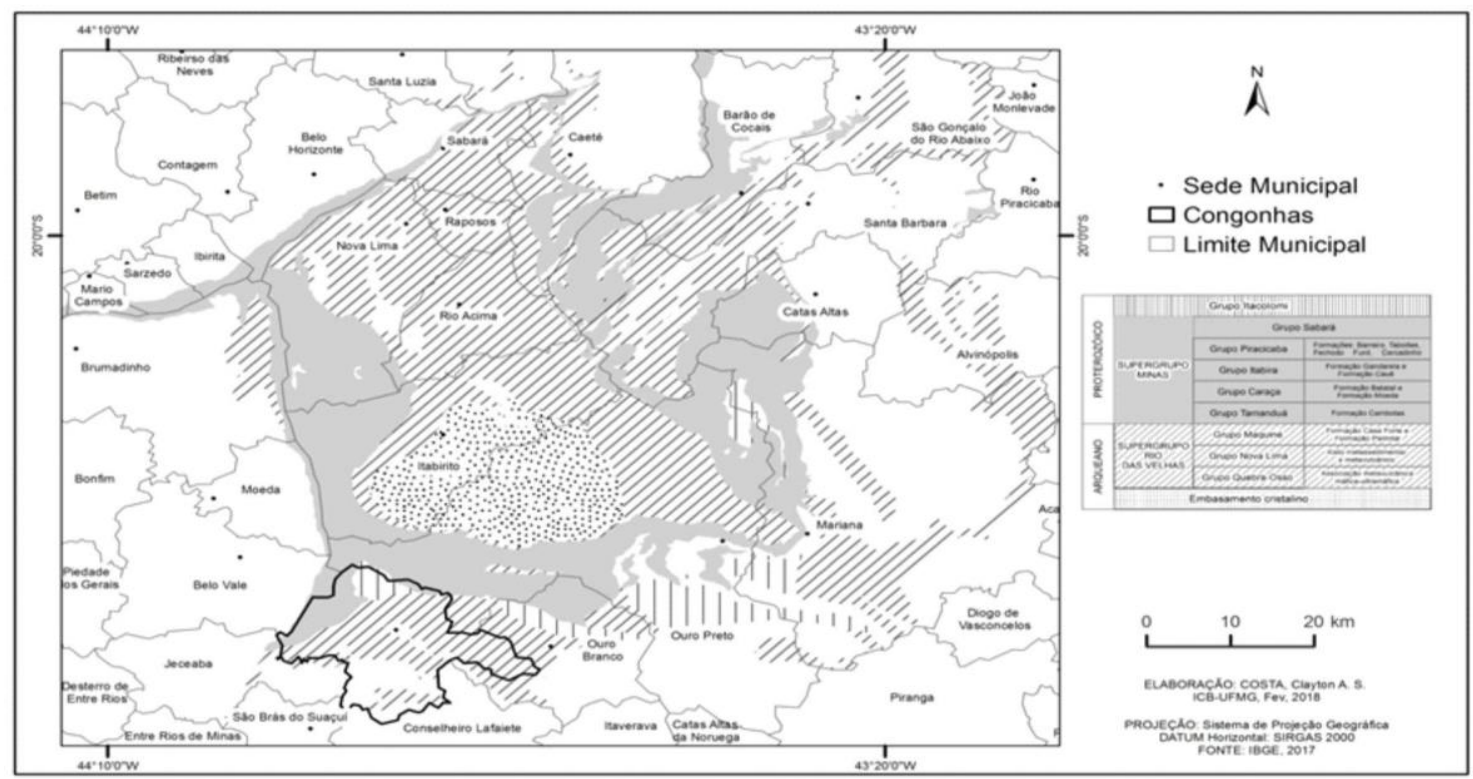

Figura 1 - Localização do município de Congonhas, Minas Gerais, Brasil, em destaque no mapa, no contexto do Quadrilátero Ferrífero

Fonte: dados da pesquisa, 2018

Além da importância no setor mineral, Congonhas recebe muitos turistas para apreciarem as obras de Aleijadinho e pela sua proximidade do Colar Metropolitano de Belo Horizonte (Figura 2). O Colar Metropolitano é formado por dezesseis cidades, contabilizando uma população superior a 550 mil habitantes. Outro atrativo econômico é a sua inserção na região do Consórcio de Desenvolvimento do Alto Paraopeba (Codap) (Figura 2). Segundo Vargas (2012), vários investimentos foram implantados na região do Codap, a exemplo da criação de distritos industriais, siderúrgicas, usinas e novas empresas mineradoras. 


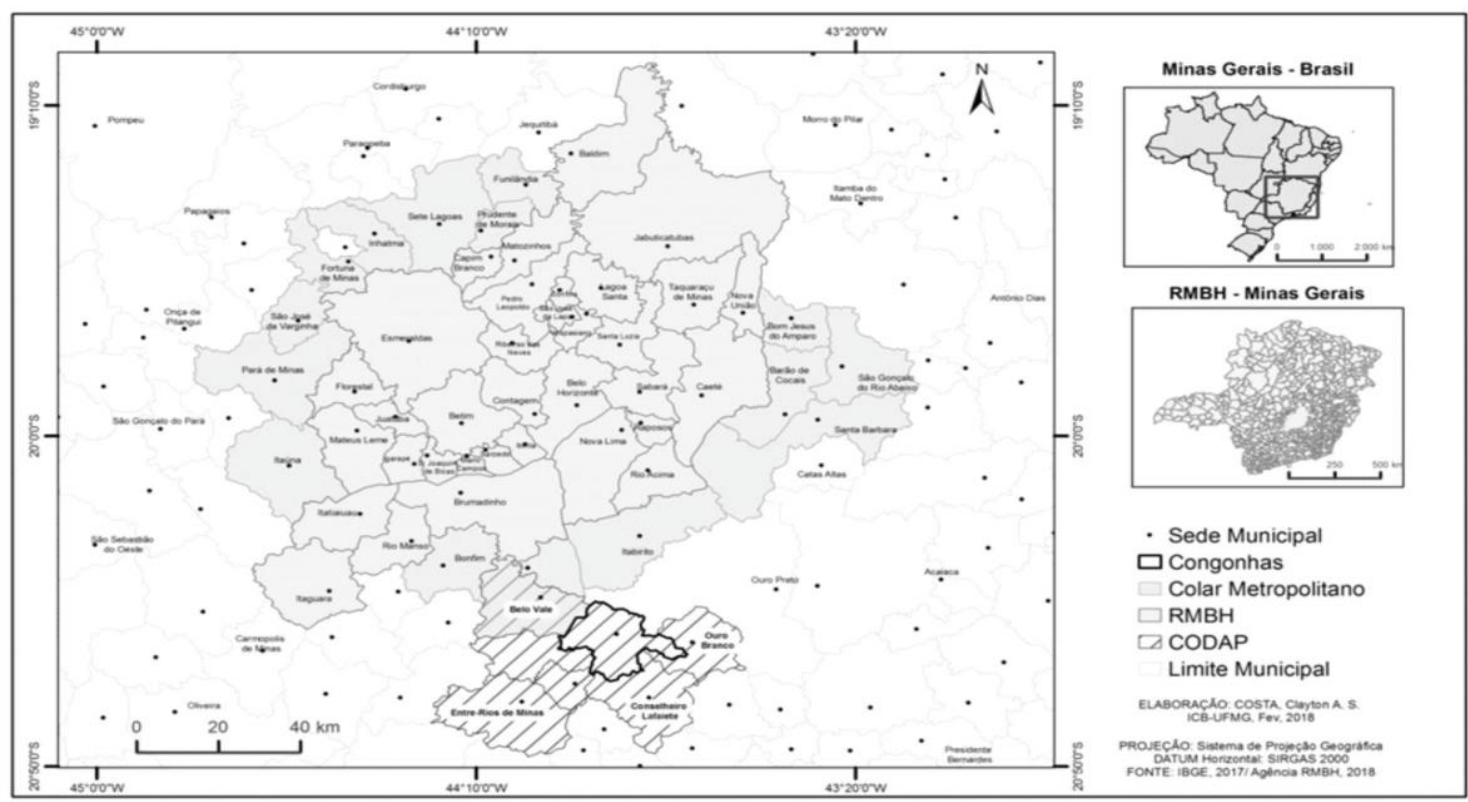

Figura 2 - Região Metropolitana de Belo Horizonte, Colar Metropolitano de Belo Horizonte e Consórcio de Desenvolvimento do Alto Paraopeba (CODAP).Fonte: dados da pesquisa, 2018

\subsection{Coleta e análise de dados}

Em maio de 2018, a Secretaria Municipal de Educação (SME) de Congonhas foi contatada para a apresentação da presente pesquisa, a ser desenvolvida em dezoito escolas do município e, no mesmo ano, um termo de anuência foi assinado. O projeto de pesquisa e os questionários utilizados foram submetidos e aprovados pelo Comitê de Ética em Pesquisa da Universidade Federal de Minas Gerais (processo número CAEE 56840616.0.0000.5149), em atendimento à Resolução no 466/2012, do Conselho Nacional de Saúde (CNS).

Foram elaborados dois modelos de questionário, um para os professores e o outro para os alunos. O questionário dos professores contém onze perguntas abertas, as quais procuraram traçar um perfil individual e caracterizar a percepção do entrevistado sobre questões e projetos ambientais, elaborados pelas escolas ou por mineradoras (Anexo A). O questionário dos alunos é composto por nove perguntas abertas, que tiveram o objetivo de traçar um perfil e avaliar sua percepção do lugar vivido, podendo contribuir para a construção de práticas educativas relacionadas à questão ambiental (Anexo B).

As respostas dos professores foram categorizadas em nominais e ordinais. Aquelas classificadas como nominais, sem ordenação dentre as categorias, receberam escores para identificá-las. Aquelas enquadradas como ordinais, com ordenação entre as categorias, receberam escores para indicar a sua importância. Como o conteúdo das respostas ordinais apresentava uma variedade muito grande de temas, adaptamos o método Sodhi et al. (2010) para diminuir as variáveis a serem analisadas. As respostas que apresentavam conteúdos abordados pela Política Nacional de Educação Ambiental (PNEA) (BRASIL, 1999) receberam pontuações maiores (número 2). Dessa forma, as respostas só receberam essa pontuação quando apresentaram o ser humano inserido na natureza, quando demonstraram a necessidade de capacitação dos professores em Educação Ambiental (EA) e quando observaram os efeitos negativos da degradação ambiental na qualidade de vida da população.

Já as respostas em que não foram observados temas centrais da PNEA, receberam uma pontuação intermediária (número 1). Essa categoria apresentava respostas em que os entrevistados observavam a sociedade desconectada da natureza, desconheciam a importância da capacitação dos profissionais em EA e não percebiam os efeitos da degradação ambiental 
afetando a qualidade de vida da população. Não houve pontuação quando os entrevistados não souberam responder ou se abstiveram de resposta. (Anexo C). A partir das respostas categorizadas e organizadas, os dados foram tratados conforme representado na Figura 3.

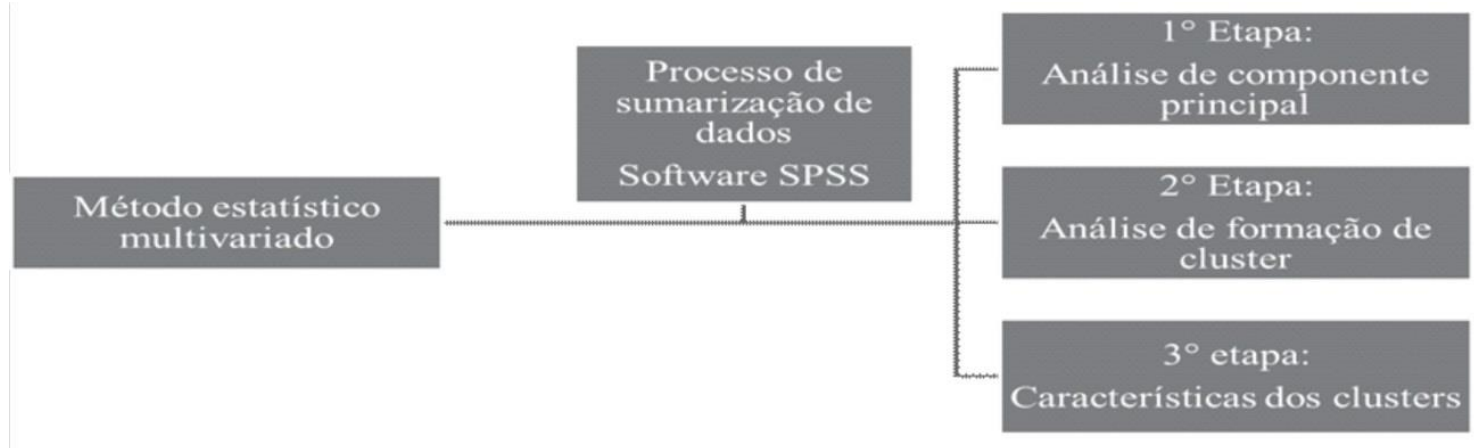

Figura 3 - Etapas do processo de sumarização de dados Fonte: dados da pesquisa, 2018

Os dados foram avaliados através de uma estatística multivariada, e com o auxílio do software da IBM Statistical Package for Social Sciences (IBM CORP., 2013).

$\mathrm{Na}$ primeira etapa, o objetivo foi reduzir a complexidade dos dados, identificando fatores e substituindo o conjunto original de variáveis por um menor em que as variáveis não estavam correlacionadas. Para tal, utilizou-se o método da Análise das Componentes Principais (ACP), que determinou as novas variáveis (componentes) que explicam a maior variabilidade possível existente em uma matriz de dados multidimensionais. Com a ACP é feita uma transformação linear de $n$ variáveis originais que podem estar correlacionadas em $n$ ' novas variáveis não correlacionadas entre si.

Os componentes principais são o resultado da conversão do conjunto de valores originais em um conjunto de variáveis lineares não correlacionadas. Esses novos conjuntos apresentam pontuações que podem ser considerados como uma medida da relativa importância de cada variável no que diz respeito aos componentes principais, indicando relações diretas ou inversamente proporcionais.

A ACP usou o método da correlação (já que as variáveis possuem ordem de grandezas diferentes) e o método Varimax para rotacionar os eixos dos componentes principais, de modo a colocar em eixos ortogonais não correlacionados em um espaço n-dimensional. Os principais componentes foram extraídos por eigenvalues superiores a 1, com um número máximo de interações igual a 25. Os escores para cada componente foram salvos usando o método de regressão e foram utilizados para estimar os clusters. Os componentes extraídos explicam de 61 a $70 \%$ da variância dos dados de entrada. Os testes estatísticos (testes KMO e Bartlett's) foram realizados para todas as ACP, com o propósito de avaliar a consistência da análise estatística realizada. Todas as análises foram conduzidas no software IBM SPSS ${ }^{\circledR}$ (IBM CORP., 2013).

A segunda etapa referiu-se ao procedimento para formar e identificar os clusters a partir dos componentes principais extraídos. Foi escolhido o número de clusters a serem testados, formados e escolhidos. Testou-se a formação com números distintos de clusters e optou-se por três agrupamentos, que melhor explicavam os dados. Os grupos foram categorizados baseados no método de Sodhi et al. (2010). Assim, grupos foram formados baseados na percepção dos efeitos da mineração (efeito socioeconômico e degradação ambiental) e da formação profissional dos professores (motivação e aperfeiçoamento profissional). A terceira etapa referiu-se à obtenção das estatísticas descritivas por meio da seleção dos casos de número de clusters e das variáveis de interesse, para distinguir os 
clusters (Anexo D). Cada variável foi analisada separadamente (análise univariada), para caracterizar a percepção de cada cluster.

Em relação às respostas dos alunos, utilizamos a metodologia de Prais e Rosa (2017) para categorizar e criar nuvem de palavras, onde os tópicos se organizam na cor cinza e em vários tamanhos, com base no número de menções feitas (Anexo E) para cada uma das perguntas que compunham o questionário aplicado. As palavras apareceram repetidas na nuvem conforme o número de citações dos entrevistados. Aqueles que não responderam as perguntas não foram incluídos na nuvem de palavras.

\section{Resultados}

\subsection{Percepção dos professores sobre questões ambientais associadas à mineração}

Por meio das análises dos questionários dos 76 professores que participaram da pesquisa, foram identificados três clusters. Sendo eles nomeados: 1- EA por predisposição e autodidata (EAPA), formado por 38 professores; 2- EA por demanda e autodidata (EADA), composto por 31 professores; 3- EA com curso de capacitação (EACC), com sete docentes. É importante salientar que cada professor está inserido em apenas um único grupo. No grupo EACC foram identificados professores que, apesar de não terem formação específica e/ou acadêmica na área da EA, frequentaram cursos de capacitação sobre o assunto. As principais características e percepções dos grupos podem ser observadas na Figura 4.

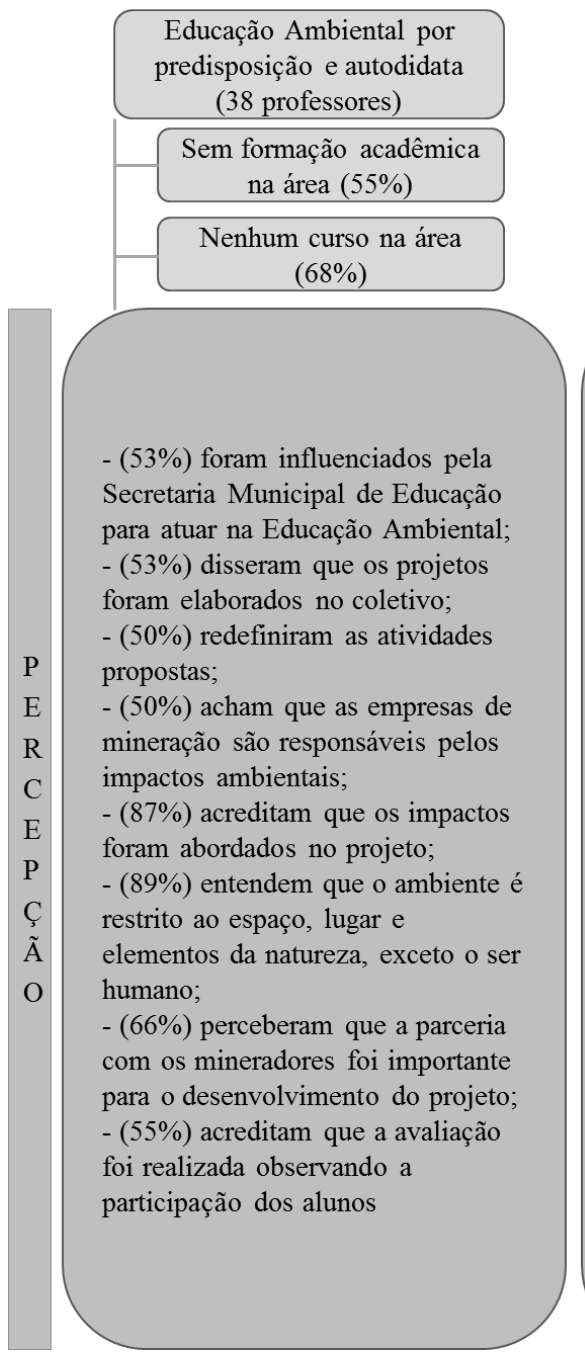

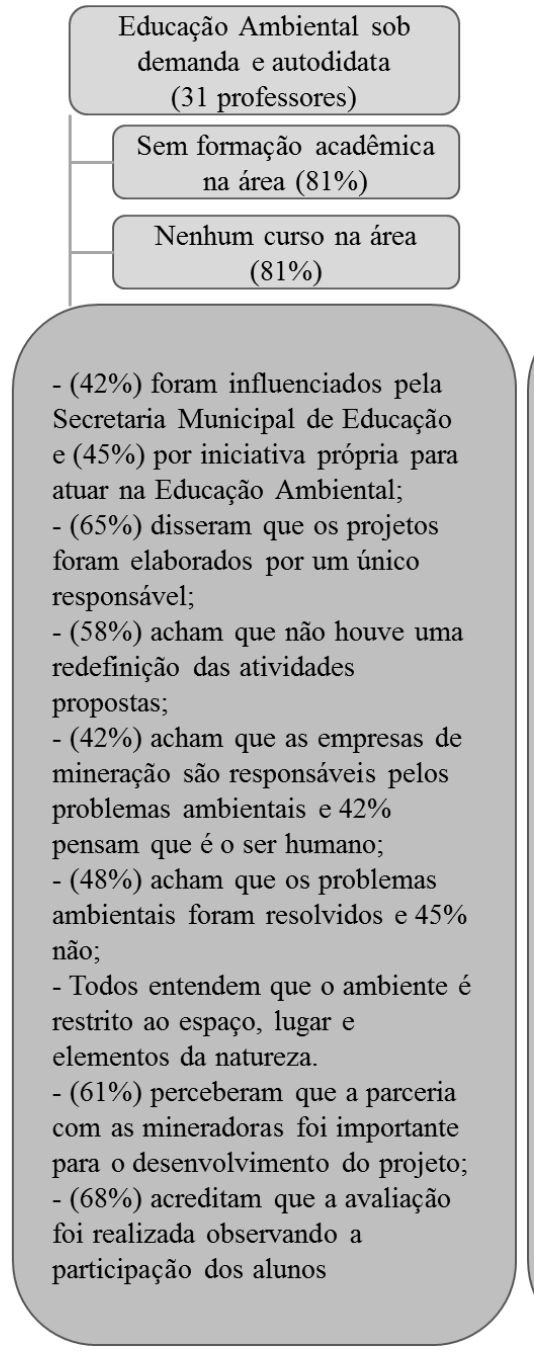

Educação Ambiental com curso de capacitação (07 professores)

Sem formação acadêmica na área $(57 \%)$

Tem curso na área (71\%)

(57\%) tiveram sua própria iniciativa para trabalhar em Educação Ambiental;

- $(42 \%)$ disseram que os projetos foram elaborados no coletivo e $29 \%$ disseram que teve um responsável;

- (57\%) acham que não houve uma redefinição das atividades propostas;

- (71\%) acham que o ser humano é responsável pelos impactos ambientais;

- Todos pensam que os impactos ambientais foram abordados;

- $(86 \%)$ entendem que o ambiente se refere à relação ser humanonatureza

- $(42 \%)$ perceberam que a parceria com as mineradoras foi o principal benefício encontrado no desenvolvimento do projeto; - $(43 \%)$ acreditam que a avaliação foi realizada observando a participação dos alunos e $43 \%$ disseram que não existiu 
Figura 4 - Características e percepções dos grupos de professores sobre os impactos associados à mineração Fonte: dados da pesquisa, 2018

Metade dos professores do grupo EAPA, disse ter sido influenciada a trabalhar com (EA) pela Secretaria Municipal de Educação (SME). Os projetos ambientais foram elaborados de forma coletiva (53\%), com a participação dos professores, pedagogos, diretores e funcionários da própria SME e, muitas vezes, com redefinição das atividades propostas. Em relação às mineradoras, $50 \%$ dos professores acreditam que elas são as responsáveis pelos impactos ambientais associados à mineração, tais como: poluição sonora, atmosférica, hídrica, desmatamento e extinção de animais. Dentre esses professores, $87 \%$ afirmaram que esses impactos são abordados nos projetos. A maioria dos professores (89\%) teve dificuldades para perceber o ser humano como parte integrante do meio ambiente. $\mathrm{O}$ desenvolvimento dos projetos foi facilitado pelas parcerias firmadas com algumas mineradoras, de acordo com $66 \%$ dos professores. A avaliação desses projetos foi realizada por meio de observação dos discentes envolvidos, segundo $55 \%$ dos professores.

Parte dos docentes do grupo EADA (42\%) foi influenciada pela SME a trabalhar a EA em projetos elaborados por esse órgão e $45 \%$ do grupo informaram que trabalharam por iniciativa própria. Já $65 \%$ dos professores desse cluster relataram que os projetos de EA foram elaborados por um único responsável da SME. Os demais informaram que não houve redefinição das atividades propostas. De acordo com $48 \%$ dos professores, os impactos ambientais vistos na cidade são abordados nos projetos. A maior parte dos professores informou que a responsabilidade desses problemas é do ser humano (42\%) e das mineradoras (42\%). Todos os professores tiveram dificuldades em identificar o ser humano como elemento natural do meio ambiente. Na opinião de $61 \%$ dos professores, a parceria com mineradoras, através de seus programas de EA, concursos como o de redação com propostas de temas ambientais e outras atividades, foram as principais facilidades percebidas no desenvolvimento dos projetos. A avaliação desses projetos foi por intermédio da observação da participação dos alunos, pelos professores, de acordo com 68\% dos docentes.

Os professores do grupo EACC apresentaram iniciativa própria para trabalhar os temas ambientais (57\%). O cluster ficou dividido em relação à elaboração dos projetos: $42 \%$ dos professores disseram que foi de forma coletiva e $29 \%$ disseram que houve um único responsável. Em relação às atividades propostas no projeto, $57 \%$ dos docentes disseram que elas não foram redefinidas. Os professores desse cluster (71\%) disseram que o ser humano é o responsável pelos impactos ambientais, e todos responderam que os impactos são abordados nos projetos. A maioria (86\%) entende que o ser humano faz parte do meio ambiente. A parceria com as mineradoras facilitou o desenvolvimento dos projetos de EA (42\%). Parte dos professores do grupo fez a avaliação do projeto com a participação dos alunos (43\%), e outros afirmaram que não houve avaliação do projeto (43\%).

\subsection{Percepção dos estudantes sobre questões ambientais associadas à mineração}

A respeito do perfil dos 2.854 alunos, matriculados entre o $4^{\circ}$ e $9^{\circ}$ ano de dezoito escolas que participaram da pesquisa, verificou-se que a maior parte $(52 \%)$ é composta pelo gênero feminino. Destes estudantes, $49 \%$ estão compreendidos na faixa etária de onze a treze anos e 54\% estão matriculados entre o $6^{\circ}$ e $8^{\circ}$ anos do ensino fundamental. A maioria dos estudantes $(46 \%)$ reside no município de Congonhas entre cinco a doze anos. A maior parte dos alunos (67\%) está matriculada em escolas que se localizam a uma distância de até $6 \mathrm{~km}$ das grandes mineradoras.

A Figura 5 apresenta a nuvem de palavras sobre os benefícios que as mineradoras oferecem à cidade quando consideradas as respostas dos alunos. Palavras como emprego, 
trabalho, dinheiro, renda e impostos foram os destaques da nuvem, mostrando que os benefícios podem estar relacionados à área da economia. As palavras gincanas, oficinas, brincadeiras e cinema, foram inseridas a um contexto socioambiental, com menor representatividade. Trata-se de atividades ofertadas pelas mineradoras sobre temáticas ambientais.

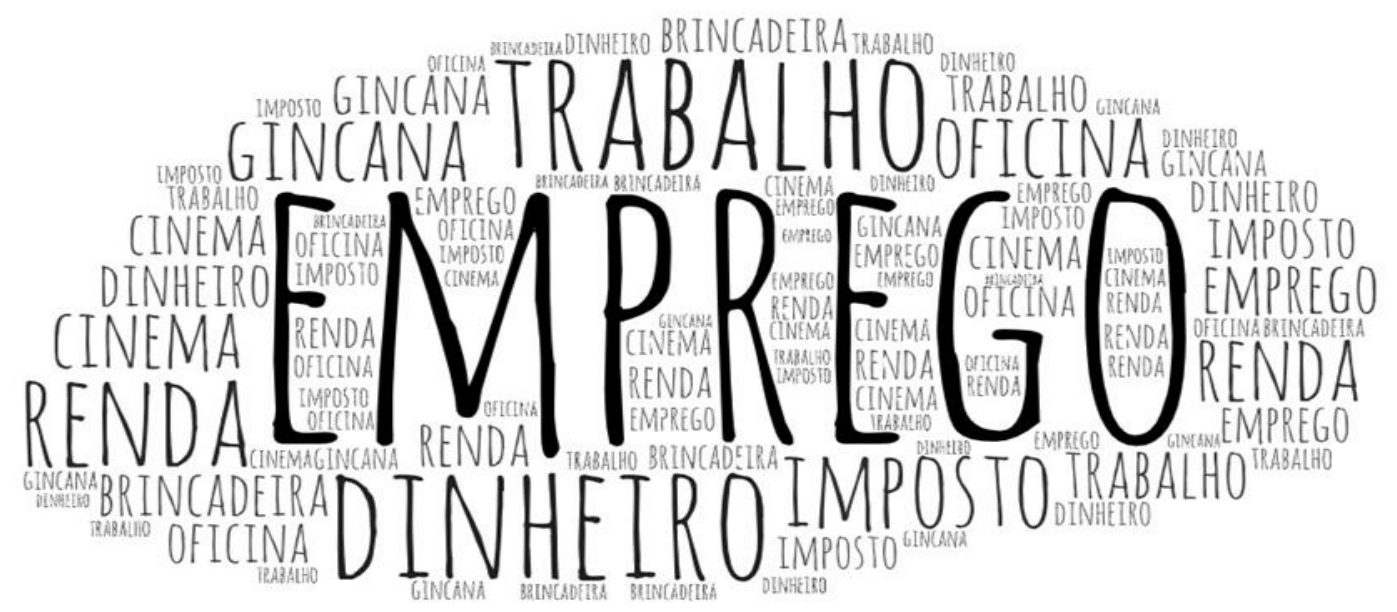

Figura 5 - Nuvem de palavras representando as categorias mais citadas pelos alunos sobre o principal benefício que as mineradoras oferecem a cidade

Fonte: dados da pesquisa, 2018

A Figura 6 representa a percepção dos alunos sobre a presença das mineradoras na cidade. Palavras como economia, dinheiro e comércio apresentaram destaque como impactos positivos, no sentido de movimentação financeira. Tais impactos sobressaíram em relação aos negativos, os quais foram representados pelas palavras poluição do ar, rejeito, congestionamento, desmatamento, destruição e violência.

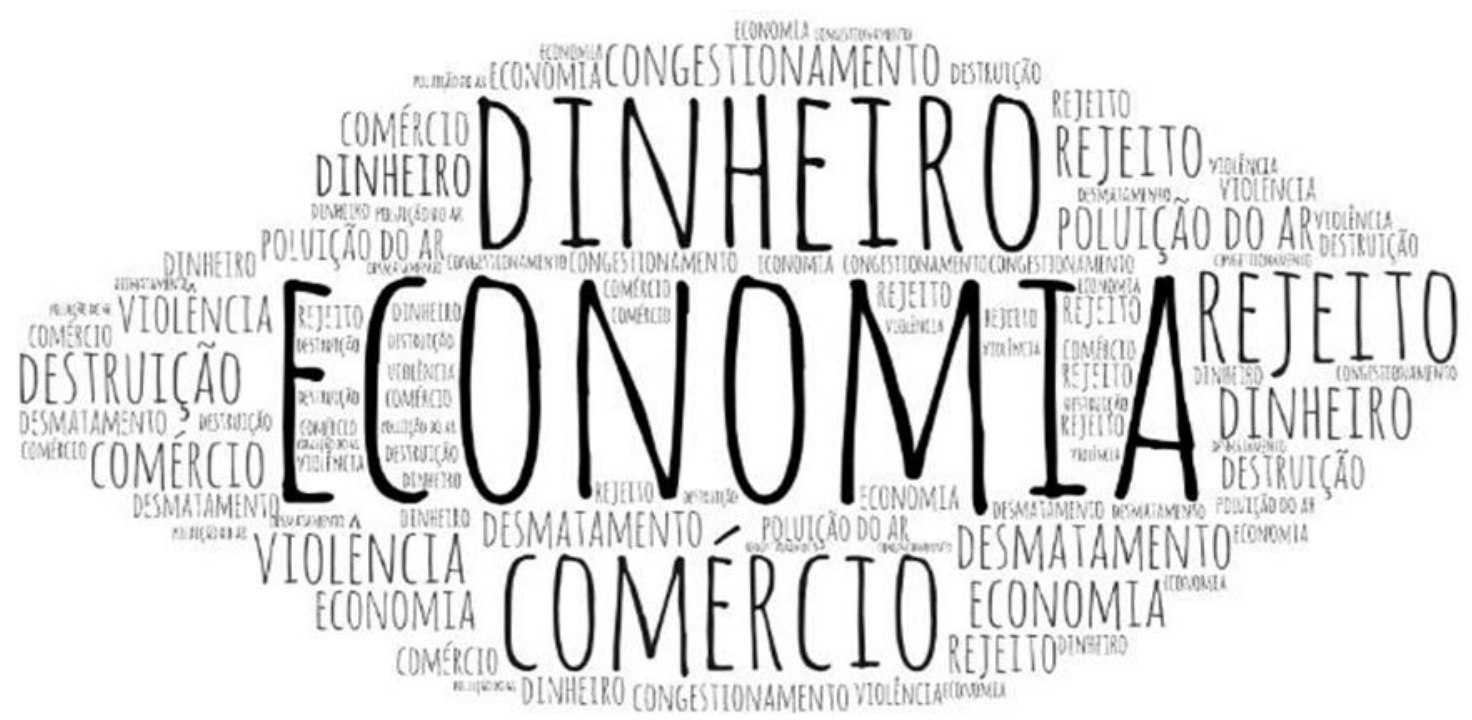

Figura 6 - Nuvem de palavras que representa as categorias mais citadas sobre a percepção dos alunos em relação a presença das mineradoras na cidade de Congonhas - MG

Fonte: dados da pesquisa, 2018

Em relação a quem sofre interferência dos problemas ambientais associados à mineração, observa-se, na Figura 7, que as palavras mais citadas foram; rinite, alergia, 
irritação, tosse e doença, indicando interferência na saúde humana. Outros componentes da natureza foram pouco citados, tais como animal, rio, solo e vegetação no sentido de impactos negativos.

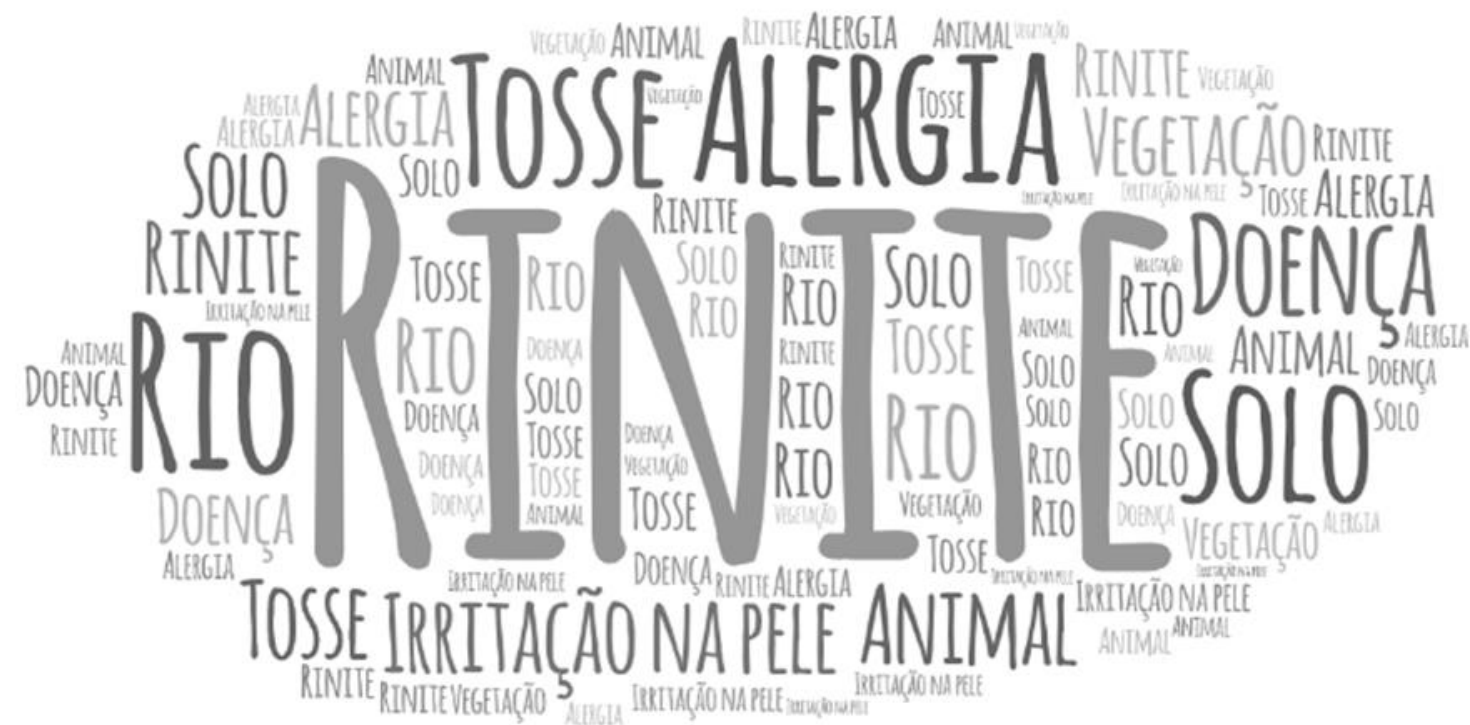

Figura 7 - Nuvem de palavras que representa as categorias mais citadas em relação a quem sofre interferência dos problemas ambientais associados à mineração

Fonte: dados da pesquisa, 2018

Quanto ao que faz parte do meio ambiente, percebe-se que os recursos naturais apresentaram destaque, tendo como palavras mais citadas árvore, pássaro, água, ar, folha, terra e inseto. As palavras pessoa, criança, eu, gente, menino, mulher e homem, como representação de elemento da natureza, tiveram pouca representatividade, conforme mostrado na Figura 8.

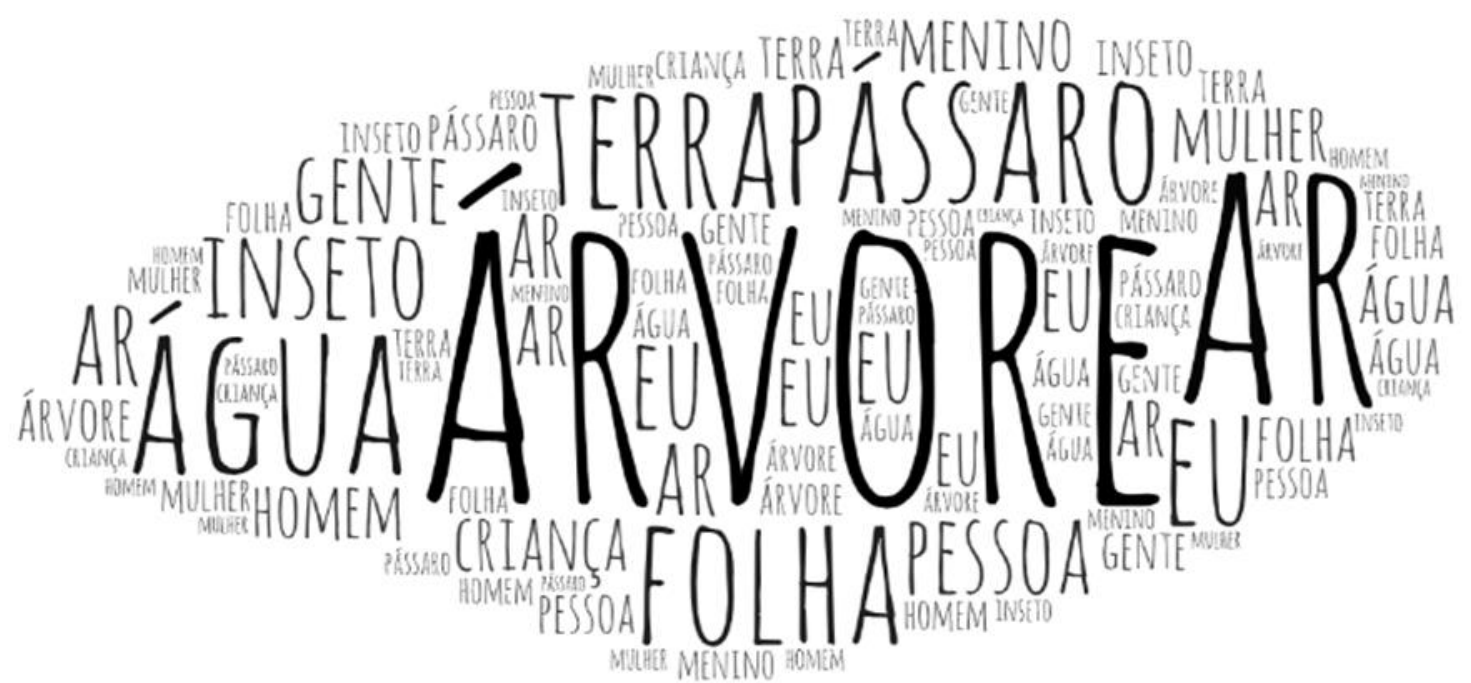

Figura 8 - Nuvem de palavras que representa as categorias citadas em relação ao que faz parte do meio ambiente Fonte: dados da pesquisa, 2018

\section{Discussão}

\subsection{Percepção dos professores sobre questões ambientais associadas à mineração}


Para que a atual percepção dos professores e dos alunos contribua para sua participação crítica nos programas de RSC, é necessário compartilhar, informar, discutir e criar ações educativas de cunho ambiental, por meio de metodologias participativas, para a elaboração de projetos ambientais com viés crítico e transformador. A avaliação da percepção dos professores e alunos pode contribuir com a construção de projetos ambientais que considerem o contexto local, alinhando-os à perspectiva da geoética. Dessa forma, abordamse os aspectos ético, social e cultural que envolvem a exploração dos recursos naturais e, ainda, o consumismo, observando os seus desdobramentos na esfera econômica, política e ambiental. Assim, tais projetos poderão contribuir para o entendimento holístico de situações socioambientais e socioeconômicas de um dado lugar, que são objetivos a serem alcançados por práticas em EA orientadas por uma perspectiva crítica.

Os estudos relacionados à RSC envolvem as comunidades localizadas próximo às minas, conforme verificado no estudo de Hilson (2002). A participação do professor torna-se estratégica, uma vez que a escola pode contribuir para identificar e avaliar as demandas da comunidade, a qual passa a ser vista como um centro comunitário (MILLER, 1993). O professor, como parte representativa da escola, pode ser considerado um ator social importante na formação de cidadãos com posturas sustentáveis (SILVA et al., 2015).

Para reforçar a figura do professor como ator social, capaz de trabalhar com as questões socioambientais, é importante que ele ultrapasse as dificuldades relativas à sua formação, capacitando-se e participando de cursos de formação continuada na área ambiental. Essas dificuldades enfrentadas pelos três grupos de professores do nosso estudo também foram identificadas por Bizerril e Faria (2001), em estudo sobre a percepção de professores referente à EA no ensino fundamental. Para reverter a situação, os autores propuseram que fossem realizadas parcerias entre centros de pesquisa e escolas para a oferta de formação continuada.

A proposta de parceria para capacitação apresentada por Bizzerril e Faria (2001) é interessante, tendo em vista o seu potencial de gerar motivação, conhecimento e compreensão a respeito dos temas ambientais. As práticas educativas em EA abordadas pelos grupos do nosso estudo, uma apoiada na modalidade autodidata e outra no aprendizado proporcionado por cursos, podem contribuir para que os professores se organizem e planejem uma proposta educativa pautada na construção do conhecimento colaborativo, coletivo ou cooperativo (ROBOTTOM; SAUVÉ, 2003). Isso é possível uma vez que os professores passaram por vivências em suas respectivas práticas, possibilitando a troca de experiências, discussões e comprometimento entre os envolvidos por meio da articulação entre seus saberes e fazeres (JACOBI; TRISTÃO; FRANCO, 2009).

As características e percepções dos grupos autodidatas EAPA e EADA são mais similares entre si quando comparadas com as do grupo EACC. O diferencial é que este último grupo tem o discernimento mais claro das interações ser humano-natureza, o que facilita a proposição de atividades e ações com uma abordagem crítica da EA. A participação em cursos compreendidos como espaços de convivência no âmbito de processos formativos, normalmente resulta em espaços de aprendizagem, de formação crítica e de criação na área ambiental (JACOBI; TRISTÃO; FRANCO, 2009).

A partir do momento que o professor apreende novos conhecimentos, ele poderá estabelecer diálogo com a mineradora e facilitar a participação de seus alunos nesse processo. Em um estudo sobre o diálogo empresa-comunidade e o conceito de responsabilidade social, Resende e Kamel (2007) ressaltaram a importância de valorizar e destacar a interação com stakeholders (grupos de interesse). Segundo os autores, o diálogo proporciona o aprender junto, partilhar significados, se educar no relacionamento com o outro, trocar experiências, estabelecer redes e construir conhecimentos por meio da coesão dos saberes transformadores de uma realidade. 
Entendemos que é interessante a escola propor a participação de setores públicos e de mineradoras em cursos e projetos ambientais, porém o professor deve ter autonomia para inserir a EA nas suas práticas educativas (CASTOR; TRISTÃO, 2015), buscando planejar e avaliar seus projetos de forma contínua e distante das atividades reducionistas, obsoletas, acríticas e desconectadas com a realidade do seu lugar vivido (DIAS, 2001). Os cursos e os projetos precisam contemplar os impactos associados à mineração, pois abordar parcialmente esses impactos pode distanciar o professor de práticas educativas pautadas no eixo açãoreflexão-ação em torno da problemática ambiental (JACOBI; TRISTÃO; FRANCO, 2009).

Assim sendo, os professores com experiências em projetos ambientais e aqueles com capacitação em EA poderiam ofertar cursos aos seus pares sem formação. O poder público também poderia estabelecer parcerias via projeto de extensão com o Instituto Federal de Minas Gerais (IFMG) campus Congonhas, para ofertar cursos de capacitação envolvendo percepção, mineração e meio ambiente. A referida instituição possui um corpo docente qualificado (mestres e doutores) e oferta um curso técnico em mineração, além de não haver empecilhos para que se firmem parcerias com outras instituições de ensino.

Jacobi, Tristão e Franco (2009) defendem a participação como eixo orientador de disseminação de conhecimentos e ações diante das situações socioambientais. A educação ambiental, de acordo com Tozoni-Reis (2006), requer que os conhecimentos sejam gerados para a aquisição de posturas sustentáveis e incorporados, de maneira contínua, interdisciplinar, democrática e participativa. Acreditamos que o ato de participar possui um caráter coletivo e colaborativo, diante da experiência de vida dos professores, capaz de conduzi-los à cultura do diálogo, da mobilização e da potência de ação.

Uma formação crítica pode levar a pessoa a refletir sobre como a atividade minerária pode ser conduzida de forma mais sustentável e, assim, participar mais efetivamente das tomadas de decisão envolvendo a relação mineração-comunidade-lugar. Em um estudo realizado na Bolívia sobre o desenvolvimento participativo local e a oportunidade de investimentos, Quiroga (2002) mostrou que a atividade de mineração levou a comunidade a perceber a relação desta com danos ambientais, desigualdade social e violência política. $\mathrm{O}$ autor apresentou como estratégia a implantação de meios de subsistência sustentáveis e alternativos, que envolvessem a participação do governo, do setor privado e de parceiros interessados.

Acreditamos que sem uma formação adequada, que considere os saberes científicos, populares, a vivência, a história, as crenças dos envolvidos em projetos ambientais e parcerias institucionais, dificilmente, os professores que fizeram parte de nosso estudo poderão participar de forma efetiva, apresentando ideias, propostas e ações para os programas de Responsabilidade Social Corporativa.

É importante estabelecer parceria entre mineradora e comunidade, para que o diálogo seja considerado uma estratégia moderna de gestão ambiental, com a promoção de práticas sustentáveis através deste (RESENDE; KAMEL, 2007). A escola pode assumir a responsabilidade de elaborar projetos ambientais com o objetivo de identificar as necessidades da comunidade e, consequentemente, ajudar a ampliar a percepção, a participação e o engajamento dos envolvidos. Posteriormente, a escola pode apresentar as demandas identificadas às mineradoras para que, juntas, possam traçar ações.

Em um estudo sobre o perfil da RSC das mineradoras em Santander, na Colômbia, Mendéz e Rodriguéz (2016) avaliaram a percepção dos funcionários sobre os elementos que precisavam ser melhorados a fim de atingir um nível de RSC positivo. O resultado indicou a falta de ferramentas para identificar as demandas das comunidades. Acreditamos que todos devem compreender a sua realidade, procurando entender a relação mineração-comunidadelugar, por meio do levantamento de informações socioambientais e atender às necessidades das partes interessadas (WARHURST; NORONHA, 2000). As informações socioambientais 
podem ser associadas às respostas de professores e alunos e, a partir de sua interpretação, atividades poderão ser elaboradas para fomentar a percepção dos sujeitos envolvidos.

No estudo de Resende e Kamel (2007) foi apresentado um exemplo de diálogo entre mineradora-comunidade que tem se revelado um importante instrumento para superação das diferenças envolvendo conflitos históricos. Trata-se da criação de uma linha telefônica de uso exclusivo da comunidade com a mineradora e a proposição de encontros periódicos para atendimento de demandas definidas em parceria. No caso deste estudo, a oferta da linha pode ser interessante na perspectiva da geoética, que, de acordo com Castro, Ruchkys e Manini, (2018) pode abranger as implicações éticas, sociais e culturais em relação aos usos dos recursos geológicos. Esse tipo de diálogo poderia contribuir para os grupos EAPA e EADA, tendo em vista que estes não consideram o ser humano como parte do meio ambiente. Essa constatação é preocupante, pois os professores podem continuar privilegiando a abordagem dos aspectos naturais nos projetos com a exclusão do ser humano. Isso pode distanciar o aluno dos aspectos socioeconômicos e ambientais imprimidos em seu lugar e, consequentemente, desestimular a sua participação em programas de RSC.

Para o desenvolvimento satisfatório de um projeto ambiental, é importante determinar o que se entende por meio ambiente e compreender a relação do ser humano com esse meio (PINTO; BORGES, 2015). A percepção atual contribui para que os grupos troquem experiências por meio do aprendizado colaborativo, principalmente com a ajuda do grupo de professores que possuem formação e/ou capacitação em EA. Esse grupo entende que o ser humano integra e interage com o meio ambiente. Conforme Chawla e Cushing (2007), a ação ambiental em escolas e comunidades demanda a capacidade de atingir propósitos trabalhando em grupo.

\subsection{Percepção dos estudantes sobre questões ambientais associadas à mineração}

O fato de estudar em escolas próximas às minas não contribuiu para a percepção dos impactos negativos gerados pelas mineradoras por parte significativa dos alunos que residem na cidade há um período de cinco a doze anos. A idade e o tempo de residência podem ser considerados fatores que influenciam a percepção das pessoas (KITULA, 2006) ao incorporarem valores e comportamentos, influenciando a maneira como cada indivíduo percebe o seu lugar (MELLAZO, 2005). Entendemos que é necessário identificar a percepção dos sujeitos acerca do lugar vivido para subsidiar a elaboração de projetos ambientais que contemplem os significados atribuídos sobre a paisagem e, assim, serem mais bem compreendidos. Marandola Jr. e Santos (2016) propõem investigar as maneiras de envolvimento da comunidade com o seu lugar, a fim de encontrar variáveis que correlacionem e expliquem a realidade socioambiental. Nesse sentido, é importante que o indivíduo ressignifique a sua percepção sobre impactos negativos e positivos.

$\mathrm{O}$ aspecto econômico foi sinalizado como impacto positivo pela maior parte dos alunos, considerado o principal benefício gerado pelas mineradoras. Uma vez instalada numa área, essa atividade é responsável por movimentar vários setores da economia local. $\mathrm{O}$ aspecto econômico como benefício também foi relatado em outros estudos (CARDOSO JR.; PAULA; LUNAS, 2018). A geração de empregos, investimentos na educação e saúde, melhorias nas estradas e fornecimento de serviços básicos, como abastecimento de água e esgotamento sanitário, foram benefícios apontados por Kitula (2006).

Residir por mais tempo na cidade não contribuiu para que a maioria dos alunos percebesse outros problemas ambientais associados à mineração, afora a poluição atmosférica e suas consequências para a saúde humana. A presença de material particulado em suspensão tem sido considerada como um dos principais problemas associados à mineração (KITULA, 2006; PANDEY; AGRAWAL; SINGH, 2014). O resultado de nossa pesquisa se assemelha 
ao de Shi e He (2012), que constataram que os moradores tendem a considerar a poluição como uma ameaça à saúde, principalmente quanto maior for o seu tempo de residência. No trabalho citado, esse resultado serviu como base de sugestões para a melhoria ambiental, o planejamento e a formulação de políticas públicas.

Nesse sentido, a elaboração dos projetos pode ser repensada para ampliar a participação da escola, das mineradoras e da comunidade. A parceria com as mineradoras pode ser mantida, a exemplo da atividade conhecida por Praça dos Biomas, por meio da qual os alunos recebem informações ambientais sobre os ecossistemas brasileiros. Embora essa atividade seja importante para a obtenção de novos conhecimentos, torna-se necessário contextualizá-la de acordo com os desdobramentos socioeconômicos e ambientais da relação mineração-comunidade-lugar.

A maior parte das propostas de atividades apresentadas pelas mineradoras possui influências da tipologia de concepção de meio ambiente antropocêntrica. De acordo com Reigota (1991), essa concepção evidencia a utilidade dos recursos naturais para a sobrevivência do ser humano. Acreditamos que essa concepção empregada pelas mineradoras reforça a necessidade dos projetos das escolas serem elaborados em um viés crítico, pautado na categoria de concepção globalizante. Essa proposta de Reigota (1991) prioriza as relações recíprocas entre natureza e sociedade. Essas relações devem ser pautadas nos desdobramentos do tempo geológico antropoceno, envolvendo os problemas socioambientais associados à mineração e incluindo o papel da comunidade, a responsabilidade social das empresas e a geoética (BADERA, 2014).

Para que a atual percepção dos alunos contribua para a sua participação crítica em futuros programas de RSC é necessário reavaliar os projetos ambientais como estratégia importante para alcançar a melhoria ambiental. Estes precisam centrar em propostas de atividades pautadas no entendimento dos alunos sobre meio ambiente, e não em presunções do que os alunos sabem e acreditam (LOUGHLAND; REID; PETOCZ, 2002). O aluno precisa perceber e entender que o ser humano faz parte do meio ambiente e que constantemente o modifica. Isso pode ajudá-lo a compreender que é necessário imprimir atitudes e posturas sustentáveis em prol da conservação do planeta Terra. $\mathrm{O}$ fato de os alunos não se reconhecerem como parte integrante do meio ambiente pode comprometer seriamente o nível de percepção sobre os aspectos político, econômico e social de seu lugar vivido, ou seja, da concepção da geoética.

Os projetos devem contemplar posturas e ações sustentáveis que, de acordo com Toaldo e Meyne (2013), impliquem a necessidade de reconsiderar e inovar conteúdos e abordagens com base nos avanços do saber ambiental. A construção desse saber pode se dar por meio das diferentes percepções condicionadas a uma educação em que a própria experiência do aluno sobre o meio ambiente é constatada e depois desafiada (LOUGHLAND; REID; PETOCZ, 2002; MELLAZO, 2005).

Em nosso estudo, os alunos descreveram o meio ambiente em uma perspectiva limitada e objetiva, apenas como um lugar que contém elementos representativos da fauna e flora. Essa visão que exclui o ser humano do ambiente parece comum entre discentes e pode ter implicações imediatas no trabalho educativo com as questões ambientais. Uma das possíveis consequências é o aluno se eximir de sua responsabilidade pelo meio ambiente. Encontramos resultado similar no estudo de Loughland, Reid e Petocz (2002). Para mudar essa situação, os projetos de EA deveriam contribuir para ampliar a visão dos alunos sobre a relação do ser humano com o ambiente onde vive.

Constatamos que o atual quadro de percepção dos impactos associados à mineração pode ser ampliado, tendo em vista que a visão dos alunos está muito restrita à saúde humana. Eles precisam tomar consciência de que a presença das mineradoras afeta muito mais do que apenas a saúde do indivíduo. Gilberthorpe e Banks (2012) concluíram que a participação das 
comunidades afetadas pela mineração pode melhorar o desenvolvimento de estratégias de RSC. Portanto, é necessário que o poder público proponha uma gestão ambiental que conecte as mineradoras, a comunidade escolar e outros segmentos da sociedade. Para isso, os projetos devem contemplar o diálogo e a participação e abordar os aspectos político, social e econômico de maneira interdisciplinar na perspectiva da geoética.

\section{Considerações Finais}

De acordo com as análises, a percepção precisa ser considerada no processo de elaboração de projetos ambientais por proporcionar a interpretação do lugar onde a comunidade vivencia suas experiências. A elaboração de tais projetos deve ser planejada em consonância com os aspectos históricos, geográficos, econômicos, sociais, políticos e ambientais para a valorização da cultura local. É imprescindível levar em consideração as implicações éticas no uso da paisagem (geoética), o papel da sociedade e a responsabilidade social das empresas.

Para que a sensibilização, conscientização e a ação da comunidade aconteçam, é necessário ter como base dos projetos a abordagem do tempo geológico antropoceno. A exploração desenfreada da natureza, principalmente dos recursos geológicos, por parte dos grandes empreendimentos, são marcas desse período. A atual percepção dos professores e alunos sobre os impactos associados à mineração compromete a participação da maioria deles em futuros programas de RSC.

Para reverter a situação ora exposta é necessário uma abordagem na perspectiva da geoética no processo de elaboração dos projetos ambientais a fim de contribuir com a percepção dos envolvidos a respeito da realidade socioambiental em que estão inseridos. A abordagem da geoética pode ser realizada a partir da contextualização dos aspectos éticos, sociais e culturais, que envolvem sujeito e lugar.

Os professores precisam de acesso facilitado a cursos de formação continuada sobre EA para melhorarem o seu entendimento sobre as questões ambientais envolvidas na exploração de recursos geológicos. Uma alternativa pode ser a busca por metodologias apoiadas em conhecimento compartilhado, em que cada professor compartilha com os seus pares o conhecimento que detém acerca de questões socioambientais associadas à mineração na perspectiva da geoética.

Essa alternativa pode ser efetivada através da elaboração de um processo de mobilização de professores e sua troca de experiências. Isso pode contribuir para a construção do saber ambiental dos envolvidos de forma interdisciplinar. É necessário reforçar a importância do estabelecimento de parcerias com institutos de pesquisa e empresas para o desenvolvimento de cursos de formação continuada dos professores. Assim, os professores terão condições de elaborarem projetos educativos que explorem temas ambientais orientados por uma perspectiva crítica de EA e embasados na perspectiva da geoética para melhorar a percepção de seus alunos. 


\section{Referências}

BADERA, J. Problems of the social non-acceptance of mining projects with particular emphasis on the European Union. A literature review. Environmental \& Socio-economic Studies, Katowice, v. 2, n. 1, p. 27-34, 2014.

BIZERRIL, M. X. A.; FARIA, D. S. Percepção de professores sobre a educação ambiental no ensino fundamental. Revista Brasileira de Estudos Pedagógicos, Brasília, v. 82, n. 200, p.1-14, Jan. 2001.

BRASIL. Casa Civil. Lei no 9.795, de 27 de abril de 1999. Dispõe sobre a Educação Ambiental, institui A Política Nacional de Educação Ambiental e dá outras providências. Brasília: Casa Civil, 1999. Disponível em: 〈http://www.planalto.gov.br/ccivil_03/leis/19795.htm〉. Acesso em: 18 ago. 2020.

CARDOSO JR., H. M.; PAULA, F. M. A.; LUNAS, D. A. L. O capital minerador e a nova dinâmica econômica e territorial do município de Alto Horizonte - Goiás. Revista de Geografia, Pelotas, v. 35, n. 2, p.54-74, Jan. 2018.

CASTOR, K. G.; TRISTÃO, M. Gira-mundos: a educação ambiental no mito e o mito na educação ambiental. Revista Eletrônica do Mestrado em Educação Ambiental, Rio Grande, v. 32, n. 1, p. 172$188,2015$.

CASTRO, P. T. A.; RUCHKYS, Ú.; MANINI, R. T. A sociedade civil organizada e o rompimento da barragem de fundão, Mariana (MG): porque é preciso difundir a geoética. Terra e Didatica, Campinas, v. 14, n. 4, p. 439-444, Dez. 2018. Disponível em:

<http://www.ppegeo.igc.usp.br/index.php/TED/article/view/13268>. Acesso em: 13 mar. 2019.

CHAWLA, L.; CUSHING, D. F. Education for strategic environmental behavior. Environmental Education Research, s/l, v. 13, n. 4, p. 437-452, Set. 2007.

DIAS, G. F. A situação da Educação Ambiental no Brasil é fractal. In: Brasil. Panorama da educação ambiental no ensino fundamental. Brasília: Ministério da Educação, 2001. p. 71-75.

GILBERTHORPE, E.; BANKS, G. Development on who seterms? CSR discourseand social realities in Papua New Guinea' sextractive industries sector. Resources Policy, s/1, v. 37, n. 2, p. 185-193, Jun. 2012.

GOBSTER, P. H.; NASSAUER, J. I.; DANIEL, T. C. The shared landscape: what does aesthetics have to do with ecology? Landscape Ecol., s/l, v. 22, n. 7, p. 959-972, May. 2007.

HILSON, G. The environmental impact of small-scale gold mining in Ghana: identifying problems and possible solutions. The Geographical Journal, London, v. 168, n. 1, p. 57-72, Mar. 2002.

INSTITUTO BRASILEIRO DE GEOGRAFIA E ESTATÍSTICA - IBGE. Censo demográfico 2010. Rio de Janeiro: IBGE, 2013.

IBM Corp. Released. IBM SPSS Statistics for Windows, Version 22.0. New York: Armonk, IBM Corp., 2013.

JACOBI, P. R.; TRISTÃO, M.; FRANCO, M. I. G. C. A função social da educação ambiental nas práticas colaborativas: participação e engajamento. Cadernos Cedes, Campinas, v. 29, n. 77, p. 63-79, Abr. 2009. 
KITULA, A. G. N. The environmental and socio-economic impacts of mining on local livelihoods in Tanzania: A case study of Geita District. Journal of Cleaner Production, s/l, , v. 14, n. 3-4, p.405-414, Jan. 2006.

LOUGHLAND, T.; REID, A.; PETOCZ, P. Young people's conceptions of environment: A phenomenographic analysis. Environmental Education Research, s/1, v. 8, n. 2, p.187-197, May. 2002.

MARANDOLA JR., E.; SANTOS, F. M. Percepção dos perigos ambientais urbanos: efeitos de lugar ou falácia ecológica? In: ENCONTRO NACIONAL DE ESTUDOS POPULACIONAIS, 17., 2010, Caxambu. Anais... Caxambu: Abep, 2016. p. 1-22. Disponível em: < http://www.abep.org.br/publicacoes/index.php/anais/article/view/2309>. Acesso em: 13 mar. 2019.

MELLAZO, G. C. A percepção ambiental e educação ambiental: uma reflexão sobre as relações interpessoais e ambientais no espaço urbano. Olhares \& Trilhas, Uberlândia, v.6, n. 6, p. 45-51, 2005.

MÉNDEZ, J. D. M.; RODRÍGUEZ, R. S. A profile of corporate social responsibility for mining companies present in the Santurban Moorland, Santander, Colombia. Global Ecology and Conservation, s/l, v. 6, p.25-35, abr. 2016.

MILLER, B. A. Rural distress and survival: The school and the importance of "Community". Journal of Research in Rural Education, Maine, v. 9, n. 2, p. 84-103, Jan. 1993.

OLIVEIRA, J. S; FILHO, J. F. P.; REZENDE, R. A.; SILVA, M. D. Análise espacial como suporte ao planejamento ambiental da região do Quadrilátero Ferrífero, Minas Gerais. Geographia Meridionalis, Pelotas, v. 3, p. 134-156, 2017.

ORGANIZAÇÃO DAS NAÇÕES UNIDAS PARA A EDUCAÇÃO, A CIÊNCIA E A CULTURA (UNESCO). Não culpe apenas o professor quando o culpado é o sistema, diz a UNESCO: Relatório de Monitoramento Global da Educação de 2017-2018 da UNESCO. Brasília: Unesco Office, 2017. Disponível em: <http://www.unesco.org/new/pt/rio-20/single-

view/news/dont_just_blame_the_teacher_when_the_system_is_at_fault-1/>. Acesso em: 19 dez. 2017.

PANDEY, B.; AGRAWAL, M.; SINGH, S. Assessment of air pollution around coal mining area: Emphasizing on spatial distributions, seasonal variations and heavy metals, using cluster and principal component analysis. Atmospheric Pollution Research, s/l, v. 5, n. 1, p.79-86, Jan. 2014.

PEREIRA, A.A.S.; COSTA, D.A.T.; BORGES, L. A. C. Percepção ambiental de pós-graduandos sobre os impactos da mineração. Revista Eletrônica do Mestrado em Educação Ambiental, Rio Grande, v. 34, n. 2, p. 238-255, Maio/Ago. 2017.

PINTO, B. C. T.; BORGES, J. L. C. (1). Uma atividade de educação ambiental em espaço não formal: potencialidades do uso de bacias hidrográficas. Revista Tempos e Espaços Em Educação, Aracajú, v. 8, n. 16, p.109-124. 2015. Disponível em: 〈https://doi.org/10.20952/revtee.v0i0.4037>. Acesso em: 18 ago. 2020.

PRAIS, J. L. S.; ROSA, V. F. Nuvem de palavras e mapa conceitual: estratégias e recursos tecnológicos na prática pedagógica. Nuances: Estudos sobre Educação, Presidente Prudente, v. 28, n. 1, p. 201-219, Abr. 2017.

QUIROGA, E. R. The case of artisanal mining in Bolivia: Local participatory development and mining investment opportunities. Natural Resources Forum, New York, v. 26, p. 127-139, Dec. 2002.

REIGOTA, M. O que é educação ambiental. São Paulo: Brasiliense, 1991. 
RESENDE, M. S. R.; KAMEL, J. A. N. Diálogo com stakeholders: ideias e experiências para a sua viabilidade. Revista Gestão Industrial, Curitiba, v. 3, n. 1, p.112-122, Jun. 2007.

ROBOTTOM, I.; SAUVÉ, L. Reflecting on participatory research in environmental education: Some issues for methodology. Canadian Journal of Environmental Education, Eric, v. 8, n. 1, p. 111-128, 2003.

SHI, X.; HE, F. The environmental pollution perception of residents in coal mining areas: A case study in the Han cheng mine area, Shaanxi Province, China. Environmental Management, s/l, v. 50, n. 4, p. 505-513, Ago. 2012.

SILVA, E.; SILVA, F. G.; SILVA, R. F. L.; SILVA, R. H.; OLIVEIRA, H. M. Avaliação do saber ambiental de professores do ensino público do município de São Bento, Paraíba. Scientia Plena, Aracajú, v. 11, n. 9, p. 0999011-8099901, Set. 2015.

SODHI, N.S. et al. Local people value environmental services provided by forested parks. Biodivers. Conserv., London, v. 19, s/n, p. 1175-1188, 2010.

TOALDO, A. M.; MEYNE, L. S. A educação ambiental como instrumento para a concretização do desenvolvimento sustentável. Revista Eletrônica do Curso de Direito da UFSM, Santa Maria, v. 8, s/n, p. 661-673, abr. 2013.

TOZONI-REIS, M. F. C. Temas ambientais como contribuições para uma metodologia educativa ambiental crítica, transformadora e emancipatória. Educar em Revista, Curitiba, s/v, n. 27, p. 93-110, Jun. 2006.

TUAN, Y-F. Topofilia: um estudo da percepção, atitude e valores do meio ambiente.Trad. Lívia de Oliveira. Londrina: Eduel, 2012.

VARGAS, G. P. Os consórcios públicos no planejamento e gestão regionalizada do território brasileiro: as experiências mineiras do COM10 e CODAP. 2012. 176 f. Dissertação (Mestrado em Geografia) - Universidade Federal de Minas Gerais, Belo Horizonte, 2012.

VEIGA, M. M.; SCOBLE, M.; McALLISTER, M. L. Mining with communities. Natural Resources Forum, New York, v. 25, s/n, p. 191-202, 2001.

WARHURST, A.; NORONHA, L. Corporate strategy and viable future land use: planning for closure from the outset of mining. Natural Resources Forum, New York, v. 24, s/n, p. 153-164, 2000.

\section{ANEXO A - QUESTIONÁRIO APLICADO A PROFESSORES SOBRE PERCEPÇÃO DOS IMPACTOS E DO PROJETO AMBIENTAL ASSOCIADO À MINERAÇÃ̃O}

Questionário aplicado aos professores
A. Você trabalha com Educação Ambiental?
B. Você tem formação acadêmica em Educação Ambiental?
(Perfil)
C. Participou de curso de capacitação em Educação Ambiental?
D. O que o levou a trabalhar Educação Ambiental?
E. Os projetos de Educação Ambiental eram elaborados de forma coletiva ou por um responsável?
F. Houve redefinição das atividades propostas no projeto de Educação Ambiental? (Caracterização da percepção)
G. Quem são os responsáveis pelos impactos ambientais associados a mineração e percebidos na cidade?
H. Os impactos ambientais associados a mineração são abordados nos projetos de Educação Ambiental?
I. O que você entende por meio ambiente?
J. Quais as facilidades apresentadas no desenvolvimento dos projetos de Educação Ambiental?
K. Como foi realizada a avaliação dos projetos de Educação Ambiental? 


\section{ANEXO B - QUESTIONÁRIO APLICADO A ESTUDANTES SOBRE PERCEPÇÃO DOS IMPACTOS AMBIENTAIS ASSOCIADOS À MINERAÇÃO}

Questionário aplicado aos alunos
A. Sexo
B. Qual a sua idade?
C. Em qual ano escolar está matriculado?
D. Quanto tempo mora em Congonhas?
E. Qual a distância mínima entre as escolas e as grandes minas?
F. Qual o principal benefício que as mineradoras oferecem a cidade? (Caracterização da percepção)
G. O que você acha da presença das mineradoras na cidade?
H. Quem sofre interferência dos problemas ambientais associados a mineração?
I. O que faz parte do meio ambiente?

\section{ANEXO C - VARIÁVEIS, CATEGORIAS E SUAS CLASSIFICAÇÕES APÓS A ANÁLISE DAS RESPOSTAS APRESENTADAS PELOS PROFESSORES}

\begin{tabular}{|c|c|c|c|}
\hline & & ofessores & \\
\hline Categorização & Classificação & Categorização & Classificação \\
\hline $\begin{array}{l}\text { A. Você trabalha com Educação } \\
\text { Ambiental? }\end{array}$ & & $\begin{array}{l}\text { G - Quem são os responsáveis pelos impactos } \\
\text { ambientais associados a mineração e } \\
\text { percebidos na cidade? }\end{array}$ & \\
\hline $2-\operatorname{Sim}$ & & 2 - Mineradoras & \\
\hline 1 - Esporadicamente & Ordinal & 1 - Homem & Nominal \\
\hline 0 - Não & & 0 - Não respondeu & \\
\hline $\begin{array}{l}\text { B. Você tem formação acadêmica em } \\
\text { educação ambiental? }\end{array}$ & & $\begin{array}{l}\text { H - Os impactos ambientais associados a } \\
\text { mineração são abordados nos projetos de } \\
\text { Educação Ambiental? }\end{array}$ & \\
\hline $2-\operatorname{Sim}$ & & $2-\operatorname{Sim}$ & \\
\hline 1 - Não & Nominal & 1 - Parcialmente & Ordinal \\
\hline $\begin{array}{l}\text { C - Participou de curso de capacitação em } \\
\text { Educação Ambiental? }\end{array}$ & & 0 - Não & \\
\hline $2-\operatorname{Sim}$ & & I - O que você entende por meio ambiente? & \\
\hline 1 - Não & Nominal & $\begin{array}{l}2 \text { - Tudo que envolve a relação homem e } \\
\text { natureza }\end{array}$ & \\
\hline $\begin{array}{l}\text { D - O que o levou a trabalhar Educação } \\
\text { Ambiental? }\end{array}$ & & $\begin{array}{l}1 \text { - Espaço, lugar, elementos da natureza exceto } \\
\text { o homem }\end{array}$ & Ordinal \\
\hline 2 - Iniciativa própria & & 0 - Não respondeu & \\
\hline $\begin{array}{l}1 \text { - Secretaria Municipal de Educação } \\
\text { SME }\end{array}$ & Ordinal & $\begin{array}{l}\mathrm{J} \text { - Quais as facilidades apresentadas no } \\
\text { desenvolvimento dos projetos de Educação } \\
\text { Ambiental? }\end{array}$ & \\
\hline 0 - Não sabe & & 2 - Parceria mineradoras & \\
\hline $\begin{array}{l}\text { E - Os projetos de Educação Ambiental } \\
\text { eram elaborados de forma coletiva ou por } \\
\text { um responsável? }\end{array}$ & & 1 - Participação escolar & Nominal \\
\hline 2 - De forma coletiva & & 0 - Não sabe & \\
\hline 1 - Através de um responsável & Nominal & $\begin{array}{l}\text { K - Como foi realizada a avaliação dos projetos } \\
\text { de Educação Ambiental? }\end{array}$ & \\
\hline 0 - Não sei & & 2 - Reuniões & \\
\hline $\begin{array}{l}\text { F - Houve redefinição das atividades } \\
\text { propostas no projeto de Educação } \\
\text { Ambiental? }\end{array}$ & & 1 - Observando a participação & Ordinal \\
\hline $2-\operatorname{Sim}$ & & 0 - Não teve & \\
\hline 1 - Não & Nominal & & \\
\hline 0 - Não sabe & & & \\
\hline
\end{tabular}


ANEXO D - NÚMERO DE CASOS E PORCENTAGENS PARA PROFESSORES Professores

\begin{tabular}{|c|c|c|c|c|}
\hline \multirow{3}{*}{ Você trabalha com Educação Ambiental? } & \multicolumn{3}{|c|}{ Número de caso de cluster } & \multirow{3}{*}{ Total } \\
\hline & 1 & 2 & 3 & \\
\hline & $\mathbf{N} \mid \mathbf{P}$ & $\mathbf{N} \mid \mathbf{P}$ & $\mathbf{N} \mid \mathbf{P}$ & \\
\hline Não & $7 \mid 18 \%$ & $7 \mid 23 \%$ & $1 \mid 14 \%$ & 15 \\
\hline Parcialmente & $4 \mid 11 \%$ & $13 \mid 42 \%$ & $229 \%$ & 19 \\
\hline Sim & $27 \mid 71 \%$ & $11 \mid 35 \%$ & $4 \mid 57 \%$ & 42 \\
\hline Total & \begin{tabular}{l|l|l}
38 & $100 \%$
\end{tabular} & $31 \mid 100 \%$ & $7 \mid 100 \%$ & 76 \\
\hline
\end{tabular}

\begin{tabular}{|c|c|c|c|c|}
\hline \multirow{3}{*}{$\begin{array}{c}\text { Você tem formação acadêmica em } \\
\text { Educação Ambiental? }\end{array}$} & \multicolumn{3}{|c|}{ Número de caso de cluster } & \multirow{3}{*}{ Total } \\
\hline & 1 & 2 & 3 & \\
\hline & $\mathbf{N} \mid \mathbf{P}$ & $\mathbf{N} \mid \mathbf{P}$ & \begin{tabular}{l|l}
$\mathbf{N}$ & $\mathbf{P}$
\end{tabular} & \\
\hline Não & $21 \mid 55 \%$ & $25 \mid 81 \%$ & $4 \mid 57 \%$ & 50 \\
\hline Sim & $17 \mid 45 \%$ & $6 \mid 19 \%$ & $3 \mid 43 \%$ & 26 \\
\hline Total & \begin{tabular}{l|l}
38 & $\mathbf{1 0 0} \%$ \\
\end{tabular} & \begin{tabular}{l|l}
31 & $100 \%$ \\
\end{tabular} & \begin{tabular}{l|l}
7 & $100 \%$
\end{tabular} & 76 \\
\hline
\end{tabular}

\begin{tabular}{|c|c|c|c|c|}
\hline \multirow{3}{*}{$\begin{array}{l}\text { Participou de curso de capacitação em Educação } \\
\text { Ambiental? }\end{array}$} & \multicolumn{3}{|c|}{ Número de caso de cluster } & \multirow{3}{*}{ Total } \\
\hline & 1 & 2 & 3 & \\
\hline & $\mathbf{N} \mid \mathbf{P}$ & $\mathbf{N} \mid \mathbf{P}$ & $\mathbf{N} \mid \mathbf{P}$ & \\
\hline $\begin{array}{l}\text { Não } \\
\text { Sim }\end{array}$ & \begin{tabular}{l|l|l}
26 & $68 \%$ \\
12 & $32 \%$
\end{tabular} & \begin{tabular}{r|l|}
25 & $81 \%$ \\
6 & $19 \%$
\end{tabular} & \begin{tabular}{l|l|l}
2 & $29 \%$ \\
5 & $71 \%$
\end{tabular} & $\begin{array}{l}53 \\
23\end{array}$ \\
\hline Total & \begin{tabular}{l|l|l}
38 & $100 \%$ \\
\end{tabular} & \begin{tabular}{l|l}
31 & $100 \%$ \\
\end{tabular} & \begin{tabular}{l|l}
7 & $100 \%$ \\
\end{tabular} & 76 \\
\hline
\end{tabular}

\begin{tabular}{|c|c|c|c|c|}
\hline \multirow{3}{*}{ O que o levou a trabalhar Educação Ambiental? } & \multicolumn{3}{|c|}{ Número de caso de cluster } & \multirow{3}{*}{ Total } \\
\hline & 1 & 2 & 3 & \\
\hline & $\mathbf{N} \mid \mathbf{P}$ & $\mathbf{N} \mid \mathbf{P}$ & $\mathbf{N} \mid \mathbf{P}$ & \\
\hline Não sabe & $4 \mid 10 \%$ & $4 \mid 13 \%$ & $2 \mid 29 \%$ & 10 \\
\hline Secretaria Municipal de Educação SME & $20 \mid 53 \%$ & $13 \mid 42 \%$ & $1 \mid 14 \%$ & 34 \\
\hline Iniciativa própria & $14 \mid 37 \%$ & $14 \mid 45 \%$ & $457 \%$ & 32 \\
\hline Total & \begin{tabular}{l|l|l}
38 & $100 \%$
\end{tabular} & $31 \mid 100 \%$ & $7 \mid \mathbf{1 0 0 \%}$ & 76 \\
\hline
\end{tabular}

\begin{tabular}{|l|r|r|r|r|}
\hline \multirow{2}{*}{$\begin{array}{c}\text { Os projetos de Educação Ambiental eram } \\
\text { elaborados de forma coletiva ou por um } \\
\text { responsável? }\end{array}$} & \multicolumn{1}{|c|}{ Número de caso de cluster } & \multirow{2}{*}{$\mathbf{2}$} & \multicolumn{1}{|c|}{$\mathbf{3}$} & \multirow{2}{*}{ Total } \\
\cline { 2 - 4 } & $\mathbf{1} \mid \mathbf{P}$ & $\mathbf{N} \mid \mathbf{P}$ & $\mathbf{N} \mid \mathbf{P}$ & \\
\hline Não sei & $7 \mid 18 \%$ & $5 \mid 16 \%$ & $2 \mid 29 \%$ & 14 \\
De forma coletiva & $20 \mid 53 \%$ & $6 \mid 19 \%$ & $3 \mid 42 \%$ & 29 \\
Através de um responsável & $11 \mid 29 \%$ & $20 \mid 65 \%$ & $2 \mid 29 \%$ & 33 \\
\hline Total & $\mathbf{3 8} \mid \mathbf{1 0 0} \%$ & $\mathbf{3 1 |} \mid \mathbf{1 0 0 \%}$ & $\mathbf{7} \mid \mathbf{1 0 0} \%$ & $\mathbf{7 6}$ \\
\hline
\end{tabular}

\begin{tabular}{|c|c|c|c|c|}
\hline \multirow{3}{*}{$\begin{array}{c}\text { Houve redefinição das atividades propostas no } \\
\text { projeto de Educação Ambiental? }\end{array}$} & \multicolumn{3}{|c|}{ Número de caso de cluster } & \multirow{3}{*}{ Total } \\
\hline & 1 & 2 & 3 & \\
\hline & \begin{tabular}{l|l}
$\mathbf{N}$ & $\mathbf{P}$ \\
\end{tabular} & \begin{tabular}{l|l}
$\mathbf{N}$ & $\mathbf{P}$ \\
\end{tabular} & \begin{tabular}{l|l}
$\mathbf{N}$ & $\mathbf{P}$ \\
\end{tabular} & \\
\hline Não sabe & $6 \mid 16 \%$ & $6 \mid 19 \%$ & $2 \mid 29 \%$ & 14 \\
\hline $\operatorname{sim}$ & $19 \mid 50 \%$ & $7 \mid 23 \%$ & $1 \mid 14 \%$ & 27 \\
\hline não & $13 \mid 34 \%$ & $18 \mid 58 \%$ & $4 \mid 57 \%$ & 35 \\
\hline Total & \begin{tabular}{l|l|l}
38 & $100 \%$ \\
\end{tabular} & \begin{tabular}{l|l|l}
31 & $100 \%$ \\
\end{tabular} & \begin{tabular}{l|l}
$700 \%$ \\
\end{tabular} & 76 \\
\hline
\end{tabular}




\begin{tabular}{|c|c|c|c|c|}
\hline \multirow{3}{*}{$\begin{array}{l}\text { Quem são os responsáveis pelos impactos } \\
\text { ambientais associados a mineração e percebidos } \\
\text { na cidade? }\end{array}$} & \multicolumn{3}{|c|}{ Número de caso de cluster } & \multirow{3}{*}{ Total } \\
\hline & 1 & 2 & 3 & \\
\hline & $\mathbf{N} \mid \mathbf{P}$ & $\mathbf{N} \mid \mathbf{P}$ & $\mathbf{N} \mid \mathbf{P}$ & \\
\hline Não respondeu & $9 \mid 24 \%$ & $5 \mid 16 \%$ & $0 \mid 0 \%$ & 14 \\
\hline Mineradoras & $1950 \%$ & $13 \mid 42 \%$ & $2 \mid 29 \%$ & 34 \\
\hline homem & $10 \mid 26 \%$ & \begin{tabular}{l|l}
13 & $42 \%$
\end{tabular} & $5 \mid 71 \%$ & 28 \\
\hline Total & \begin{tabular}{l|l|l}
38 & $100 \%$
\end{tabular} & \begin{tabular}{l|l|}
31 & $100 \%$
\end{tabular} & \begin{tabular}{l|l|l}
7 & $100 \%$ \\
\end{tabular} & 76 \\
\hline
\end{tabular}

\begin{tabular}{|c|c|c|c|c|}
\hline \multirow{3}{*}{$\begin{array}{c}\text { Os impactos ambientais associados a mineração } \\
\text { são abordados nos projetos de Educação } \\
\text { Ambiental? }\end{array}$} & \multicolumn{3}{|c|}{ Número de caso de cluster } & \multirow{3}{*}{ Total } \\
\hline & 1 & 2 & 3 & \\
\hline & $\mathbf{N} \mid \mathbf{P}$ & $\mathbf{N} \mid \mathbf{P}$ & $\mathbf{N} \mid \mathbf{P}$ & \\
\hline Não & $1 \mid 2 \%$ & $14 \mid 45 \%$ & $0 \mid 0 \%$ & 15 \\
\hline Parcialmente & $4 \mid 11 \%$ & $2 \mid 7 \%$ & $0 \mid 0 \%$ & \\
\hline $\operatorname{Sim}$ & $33 \mid 87 \%$ & $15 \mid 48 \%$ & \begin{tabular}{l|l}
7 & $100 \%$
\end{tabular} & 55 \\
\hline Total & \begin{tabular}{l|l|}
38 & $100 \%$
\end{tabular} & \begin{tabular}{l|l}
31 & $100 \%$
\end{tabular} & \begin{tabular}{l|l|l}
7 & $100 \%$ \\
\end{tabular} & 76 \\
\hline
\end{tabular}

\begin{tabular}{|c|c|c|c|c|}
\hline \multirow{3}{*}{ O que você entende por meio ambiente? } & \multicolumn{3}{|c|}{ Número de caso de cluster } & \multirow{3}{*}{ Total } \\
\hline & 1 & 2 & 3 & \\
\hline & \begin{tabular}{l|l}
$\mathbf{N}$ & $\mathbf{P}$ \\
\end{tabular} & \begin{tabular}{l|l}
$\mathbf{N}$ & $\mathbf{P}$ \\
\end{tabular} & \begin{tabular}{l|l}
$\mathbf{N}$ & $\mathbf{P}$
\end{tabular} & \\
\hline Não respondeu & $3 \mid 8 \%$ & 0 & $\overline{0}$ & 3 \\
\hline $\begin{array}{l}\text { Espaço, lugar, elementos da natureza exceto o } \\
\text { homem }\end{array}$ & $34 \mid 89 \%$ & $31 \mid 100 \%$ & $1 \mid 14 \%$ & 66 \\
\hline Tudo que envolve a relação homem e natureza & $1 \mid 3 \%$ & 0 & $6 \mid 86 \%$ & 7 \\
\hline Total & \begin{tabular}{l|l|l}
38 & $100 \%$ \\
\end{tabular} & \begin{tabular}{l|l}
31 & $100 \%$ \\
\end{tabular} & \begin{tabular}{l|l|l|l}
7 & $100 \%$ \\
\end{tabular} & 76 \\
\hline
\end{tabular}

\begin{tabular}{|l|c|c|c|r|}
\hline \multirow{3}{*}{$\begin{array}{c}\text { Quais as facilidades apresentadas no } \\
\text { desenvolvimento dos projetos de Educação }\end{array}$} & \multicolumn{3}{|c|}{ Número de caso de cluster } & \multirow{2}{*}{ Ambiental? } \\
\cline { 2 - 5 } & $\mathbf{1}$ & $\mathbf{2}$ & $\mathbf{3}$ & Total \\
\cline { 2 - 5 } & $\mathbf{N} \mid \mathbf{P}$ & $\mathbf{N} \mid \mathbf{P}$ & $\mathbf{N} \mid \mathbf{P}$ & \\
\hline Não sabe & $5 \mid 13 \%$ & $5 \mid 16 \%$ & $2 \mid 29 \%$ & 12 \\
Participação escolar & $8 \mid 21 \%$ & $7 \mid 23 \%$ & $2 \mid 29 \%$ & 17 \\
Parceria mineradoras & $25 \mid 66 \%$ & $19 \mid 61 \%$ & $3 \mid 42 \%$ & 47 \\
\hline Total & $\mathbf{3 8} \mid \mathbf{1 0 0} \%$ & $\mathbf{3 1} \mid \mathbf{1 0 0} \%$ & $\mathbf{7} \mid \mathbf{1 0 0 \%}$ & $\mathbf{7 6}$ \\
\hline
\end{tabular}

Como foi realizada a avaliação dos projetos de Educação Ambiental?

Não existe

Observando a participação

Reuniões

Total

\begin{tabular}{|c|c|c|c|}
\hline \multicolumn{3}{|c|}{ Número de caso de cluster } & \multirow[b]{2}{*}{ Total } \\
\hline 1 & 2 & 3 & \\
\hline \begin{tabular}{l|l}
$\mathbf{N}$ & $\mathbf{P}$ \\
\end{tabular} & \begin{tabular}{l|l}
$\mathbf{N}$ & $\mathbf{P}$ \\
\end{tabular} & \begin{tabular}{l|l}
$\mathbf{N}$ & $\mathbf{P}$ \\
\end{tabular} & \\
\hline $9 \mid 24 \%$ & $10 \mid 32 \%$ & $3 \mid 43 \%$ & \\
\hline $21 \mid 55 \%$ & $2168 \%$ & $3 \mid 43 \%$ & \\
\hline $8 \mid 21 \%$ & $0 \mid 0 \%$ & $1 \mid 14 \%$ & \\
\hline $38 \mid 100 \%$ & $31 \mid 100 \%$ & \begin{tabular}{l|l}
7 & $100 \%$
\end{tabular} & 7 \\
\hline
\end{tabular}

ANEXO E - NÚMERO DE MENÇÕES FEITAS PELOS ESTUDANTES POR PERGUNTAS

\begin{tabular}{lccc}
\hline \multicolumn{4}{c}{ Perguntas e respostas } \\
\hline & Qual o principal benefício que as mineradoras oferecem a cidade? & 211 \\
\hline Emprego & 542 & Gincana & 172 \\
Trabalho & 419 & Oficina & 155 \\
Dinheiro & 302 & Brincadeira & 103 \\
Renda & 255 & Cinema & 476 \\
Imposto & 219 & Não responderam & $\mathbf{2 . 8 5 4}$ \\
\hline \multicolumn{4}{c}{ Total } \\
\hline \multicolumn{4}{c}{ Perguntas e respostas } \\
\hline
\end{tabular}




\begin{tabular}{llll}
\hline Economia & 494 & Congestionamento & 200 \\
Dinheiro & 433 & Desmatamento & 199 \\
Comércio & 380 & Destruição & 157 \\
Poluição do ar & 236 & Violência & 139 \\
Rejeito & 211 & Não responderam & 405 \\
\hline & & Total & $\mathbf{2 . 8 5 4}$ \\
\hline
\end{tabular}

\section{Perguntas e respostas}

Quem sofre a interferência dos problemas ambientais associados à mineração?

\begin{tabular}{|c|c|c|c|}
\hline Renite & 446 & Animal & 131 \\
\hline Alergia & 416 & Rio & 127 \\
\hline Irritação na pele & 167 & Solo & 115 \\
\hline Tosse & 149 & Vegetação & 97 \\
\hline \multirow[t]{2}{*}{ Doença } & 147 & Não responderam & 1.059 \\
\hline & & Total & 2.854 \\
\hline \multicolumn{4}{|c|}{$\begin{array}{c}\text { Perguntas e respostas } \\
\text { O que faz parte do meio ambiente? }\end{array}$} \\
\hline Árvore & 636 & Pessoa & 147 \\
\hline Pássaro & 398 & Criança & 145 \\
\hline Água & 321 & $\mathrm{Eu}$ & 139 \\
\hline $\mathrm{Ar}$ & 212 & Gente & 137 \\
\hline Folha & 152 & Menino & 135 \\
\hline Terra & 150 & Mulher & 67 \\
\hline \multirow[t]{2}{*}{ Inseto } & 149 & Homem & 66 \\
\hline & & Total & 2.854 \\
\hline
\end{tabular}

